\title{
Immunotherapies in Early and Advanced Renal Cell Cancer
}

\author{
Benjamin Kasenda • James Larkin • Martin Gore \\ Medical Oncology, Royal Marsden Hospital, London, UK
}

\begin{abstract}
The development of new immunomodulatory monoclonal antibodies targeting the CTLA-4 or PD-1 axis has led to a revival of research on immunotherapies in solid tumours including renal cell cancer (RCC). The initial results observed with these monoclonal antibodies in the treatment of advanced melanoma have resulted in considerable interest in this treatment strategy in all tumour types. Preliminary data of these new antibodies in advanced RCC are promising and they have good safety profiles. Response rates are low but durable tumour control has been observed in some patients. However, at the moment there is no evidence that targeting the CTLA-4 or PD- 1 axis provides a substantial clinical benefit compared to established treatment with tyrosine kinase or mTOR inhibitors. There are also no reliable predictive markers. At the moment, several randomised trials have been initiated to investigate the new immunomodulatory antibodies either as single agents or in combination with anti-VEGF targeted therapy. Vaccines have continued to be investigated in advanced and adjuvant settings. No trial has so far established vaccines as a standard treatment in either situation. There are still large randomised trials ongoing investigating the potential benefit of a vaccine in combination with standard tyrosine kinase inhibitor therapy. In this chapter we will summarise selected studies on immunotherapy in advanced RCC with a focus on anti-PD-1, anti-PD-L1, and anti-CTLA-4 antibodies. We will also touch briefly on the adjuvant situation and tumour vaccines.
\end{abstract}

() 2015 S. Karger AG, Basel

Vascular endothelial growth factor (VEGF) inhibitors and mTOR inhibitors are now considered standard treatment in advanced or metastatic renal cell cancer (RCC) [1]. Previously, in Europe immunotherapy with interferon-alpha (IFN- $\alpha$ ) was the standard treatment for advanced renal cancer, and in the USA interleukin-2 (IL-2) was used in fit patients. Treatment with IFN- $\alpha$ was based on several randomised trials [2-4] and a Cochrane meta-analysis from 2006 which confirmed a 
statistically significant survival benefit for IFN- $\alpha$ (OR for death at 1 year $=0.56,95 \%$ CI 0.40-0.77) compared to non-immunotherapies [5]. The absolute survival benefit was about $15 \%$ at 1 year with an increase in median survival benefit in the region of 4 months. Studies of IL-2 suggested that treatment with high-dose (HD) intravenous schedules could lead to durable remission rates in $5-10 \%$ of patients [6-9], but there was no advantage based on randomised comparisons to controls not receiving HD IL-2. A randomised trial was conducted to test whether the combination of IFN- $\alpha$, low-dose IL-2 and 5-fluorouracil is superior to IFN- $\alpha$ alone. The response rate in the combination arm was higher (23 vs. $16 \%$ ), but there was no difference in progression-free (PFS) or overall survival (OS) [10]. Currently, particularly in the USA, some units still use HD IL-2 in selected patients, and IFN- $\alpha$ treatment is still part of European guidelines, but only in combination with bevacizumab based on two randomised trials $[1,11,12]$. The question remains whether the combination of bevacizumab with IFN- $\alpha$ is superior to bevacizumab alone.

New immunomodulatory monoclonal antibodies that target the inhibitory crosstalk between tumour cells and the immune system via the CTLA-4 or PD-1 axis have recently become available. These new antibodies have revolutionised the treatment of metastatic melanoma [13-16] and have also shown promising activity in heavily pretreated Hodgkin lymphomas [17] and squamous cell lung cancer [18]. In this chapter we will summarise selected studies on immunotherapy in advanced RCC with a focus on anti-PD-1, anti-PD-L1 and anti-CTLA-4 antibodies. We will only briefly discuss adjuvant therapy and tumour vaccines.

\section{Anti-CTLA-4 Therapy}

Two CTLA-4 antibodies, namely ipilimumab [19] and tremelimumab [20], have been investigated in non-randomised studies enrolling 51 and 19 patients with RCC, respectively. Yang et al. [19] treated 2 cohorts with ipilimumab: cohort A had a loading dose of $3 \mathrm{mg} / \mathrm{kg}$ followed by $1 \mathrm{mg} / \mathrm{kg}$ (21 patients) every 3 weeks, and cohort B received all doses at $3 \mathrm{mg} / \mathrm{kg}$ every 3 weeks (40 patients). Treatment was given for up to 1 year until disease progression or significant toxicities. Major toxicities were enteritis and endocrine deficiencies, with 33\% experiencing grade $3 / 4$ immune-mediated side effects. Overall, 6 out of 51 (12\%) patients achieved a partial remission (1 in cohort A, 5 in cohort B) with response durations ranging from 7 to 21 months. In the smaller phase I study, Rini et al. [20] treated patients with a combination of tremelimumab $(6,10$ or $15 \mathrm{mg} / \mathrm{kg}$ ) plus sunitinib (50 mg, 4 weeks on 2 weeks off treatment, or $37.5 \mathrm{mg}$ daily without interruptions). Among patients who received continuous sunitinib $37.5 \mathrm{mg}$ daily, 1 of the 7 patients who received tremelimumab $10 \mathrm{mg} / \mathrm{kg}$ plus sunitinib suffered a sudden death. Overall, rapid-onset renal failure was the most common dose-limiting toxicity $(10 \%)$. Nine out of 21 patients $(43 \%)$ who were 
evaluable for response achieved partial responses. This combination was not recommended for further development because of the unexpected serious renal toxicity [20].

\section{Anti PD-1 and PD-L1 Therapy}

Topalian et al. [21] reported a phase I trial of nivolumab (PD-1 antibody) in various solid tumours ( $\mathrm{n}=296)$ including RCC. Overall, in $14 \%$ of patients, grade $3 / 4$ drugrelated adverse events occurred, including three deaths from pulmonary toxicity. Thirty-three patients with RCC were treated, 17 with $1 \mathrm{mg} / \mathrm{kg}$ and 16 with $10 \mathrm{mg} /$ $\mathrm{kg} ; 6 \%$ discontinued treatment due to adverse events. The respective response rates in the different dosing groups were $24 \%$ and $31 \%$, with the same proportion of patients achieving stable disease ( $24 \%$ and $31 \%$, respectively) [21]. In a recent update reporting a longer follow-up, the median PFS was 7.3 months and median OS was not reached. Even after discontinuation of nivolumab, durable responses were seen [22]. In a randomised phase II trial including patients pre-treated with anti-VEGF drugs $(\mathrm{n}=168)$, three doses of nivolumab were compared: $0.3,3$ and $10 \mathrm{mg} / \mathrm{kg}$ once every 3 weeks [23]. The median PFS was 2.7, 4.0 and 4.2 months, respectively; response rates were about $20 \%$ in each group. The respective median OS in the 3 - and 10 -mg group was 25.5 and 24.7 months, respectively, and 18.2 months in the group receiving $0.3 \mathrm{mg}$. A durable response continuing for $>24$ months occurred in 14 out of 35 patients who achieved a response. The most common treatment-related adverse event was fatigue (24-35\%) and, overall, 19 patients experienced grade $3 / 4$ treatment-related toxicities [23]. The authors concluded that nivolumab demonstrated anti-tumour activity with the potential of long-term tumour control and toxicities were manageable across the three doses studied. No dose-response relationship was detected as measured by PFS [23]. A phase I trial of the PD-L1 antibody MPDL3280A in 53 patients with RCC treated 2 patients with $3 \mathrm{mg} / \mathrm{kg}, 12$ patients with $10 \mathrm{mg} / \mathrm{kg}, 18$ patients with $15 \mathrm{mg} / \mathrm{kg}$ and 21 patients with $20 \mathrm{mg} / \mathrm{kg}$. Treatment was administered every 3 weeks for up to 1 year [24]. Overall, grade 3/4 adverse events occurred in $43 \%$ of patients with hypophosphatemia, fatigue, dyspnoea and hyperglycaemia being the most common side effects. However, only $13 \%$ of these events were considered attributable to the study drug and, of note, no grade $3 / 4$ pneumonitis or diarrhoea occurred. One case of myasthenia gravis was reported and, retrospectively, this patient was found to have anti-acetylcholine receptor antibodies prior to starting therapy. The 24-week PFS was 50\% and there was some evidence for a positive correlation between the tumour PD-L1 status and clinical efficacy [24]. This PD-L1 antibody (MPDL3280A) was further investigated in combination with bevacizumab in another phase I trial which included patients with various solid tumours $(\mathrm{n}=71), 12$ of whom had RCC [24]. Ten of these patients were receiving first-line treatment. Patients with RCC received MPDL3280A $20 \mathrm{mg} /$ 
$\mathrm{kg}$ in combination with bevacizumab $15 \mathrm{mg} / \mathrm{kg}$ every 3 weeks. An objective response was observed in $30 \%$ of the RCC patients. Overall, grade $3 / 4$ toxicities occurred in $49 \%$ of patients, with abdominal pain, pneumonia and hypertension being the most frequent [25]. Brahmer et al. [26] reported a phase I trial investigating another PDL1 antibody (BMS-936559) in patients with various solid tumours $(\mathrm{n}=207)$, including 17 patients with advanced RCC. Overall, treatment was well tolerated, with grade $3 / 4$ toxicities only occurring in $9 \%$ of all patients. All patients with RCC were treated with $10 \mathrm{mg} / \mathrm{kg}$ every 2 weeks. An objective response was observed in 2 patients (12\%), with respective response durations of 4 and 17 months; $53 \%$ of patients remained progression-free at 24 weeks. Seven of 17 (41\%) renal cancer patients showed stabilization of the disease for at least 24 weeks [26].

In summary, ipilimumab, anti-PD-1 and anti-PD-L1 antibodies have shown promising clinical activity and, although response rates to single-agent therapy are not high (20-25\%), there seems to be a good chance for long-term tumour control in some patients. The safety profile is similar to that previously encountered with these agents. However, the onset of acute renal failure with the combination of tremelimumab and sunitinib was not expected. Some studies have suggested a positive correlation between tumour PD-L1 expression and response to anti-PD-1 or anti-PD-L1 therapy. Interestingly, in pre-specified subgroup analyses from a randomised phase III trial in advanced melanoma (nivolumab vs. dacarbazine), patients with a positive PD-L1 status seemed to have a higher response compared to PD-L1 negatives (53\% vs. $33 \%$ ); however, OS was very similar [16]. No interaction analyses were conducted; therefore, whether PD-L1 expression is a reliable predictive marker in melanoma remains to be determined.

In RCC, there is some evidence that PD-L1 expression may have some prognostic impact on survival; increased PD-L1 expression retrieved from archival tissue was inversely correlated with survival [27-29]. However, whether PD-L1 expression on tumour tissue in RCC could be a reliable predictive biomarker is subject to further research, especially regarding the standardization of expression level analyses and definition of appropriate cut-offs.

\section{Combinations}

\section{Anti-CTLA-4 and Anti-PD-1}

Hammers et al. [30] presented a phase I trial investigating the combination of nivolumab and ipilimumab in patients with RCC. This trial also includes a cohort of patients treated with a combination of nivolumab plus sunitinib or pazopanib (see below) [31]. Previously treated or treatment-naïve patients were randomised to receive either 4 cycles of nivolumab $3 \mathrm{mg} / \mathrm{kg}$ plus ipilimumab $1 \mathrm{mg} / \mathrm{kg}(\mathrm{N} 3+\mathrm{I} 1)$ or nivolumab $1 \mathrm{mg} / \mathrm{kg}$ plus ipilimumab $3 \mathrm{mg} / \mathrm{kg}(\mathrm{N} 3+\mathrm{I} 1)$ every 3 weeks; both groups received maintenance nivolumab $3 \mathrm{mg} / \mathrm{kg}$ every 2 weeks until progression or 
intolerable toxicity [30]. There were 21 patients in the first group and 23 in the second. Treatment-related adverse events were seen in 39 patients (89\%), 8 (18\%) discontinued treatment due to adverse events, 6 of whom were treated with $\mathrm{N} 1+\mathrm{I} 3$. Grade 3/4 adverse events occurred in 20 patients (46\%), most of these (14 patients) were treated with $\mathrm{N} 1+\mathrm{I} 3$. Response rates were $43 \%(\mathrm{~N} 3+\mathrm{I} 1)$ and $48 \%(\mathrm{~N} 1+\mathrm{I} 3)$ with a median duration of response of 7.2 months in the $\mathrm{N} 3+\mathrm{I} 1$ group; the median was not reached in the $\mathrm{N} 1+\mathrm{I} 3$ group. The median PFS was very similar for both groups: 8.4 months $(\mathrm{N} 3+\mathrm{I} 1)$ versus 8.8 months $(\mathrm{N} 1+\mathrm{I} 3)$ [30]. These encouraging results led to the initiation of a randomised phase III trial to test the superiority of the $\mathrm{N} 3+$ I1 combination compared to sunitinib in treatment-naïve patients (CheckMate 214, NCT02231749).

\section{Anti PD-1 with Tyrosine Kinase Inhibitors}

Amin et al. [31] reported a phase I trial of a combination of nivolumab $(2 \mathrm{mg} / \mathrm{kg}$ initial and $5 \mathrm{mg} / \mathrm{kg}$ expansion cohort; 3 times weekly) with either sunitinib (50 mg, 4 weeks on and 2 weeks off treatment) or pazopanib (800 mg daily, continuously). Thirty-four patients with RCC were enrolled, 14 received nivolumab in combination with sunitinib (7 in the expansion cohort) and 20 received nivolumab $2 \mathrm{mg} / \mathrm{kg}$ plus pazopanib. There were 4 dose-limiting toxicities in the pazopanib arm, which was therefore closed and no expansion cohort was started; these toxicities were elevated ALT/AST (3 patients) and fatigue (1 patient). Overall, grade $3 / 4$ adverse events were observed in $73 \%$ of patients in the sunitinib arms and in $60 \%$ in the pazopanib arm. The most common grade $3 / 4$ adverse events in the sunitinib arms included elevated ALT (18\%), hypertension (15\%) and hyponatraemia (15\%). In the pazopanib arm, elevated ALT/AST (20\% each) and fatigue (15\%) were the most frequent grade $3 / 4$ adverse events [31]. One patient treated with nivolumab $5 \mathrm{mg} /$ $\mathrm{kg}$ plus sunitinib developed grade 3 pneumonitis. In those patients treated with the sunitinib combination, 8 patients $(24 \%)$ had to discontinue treatment because of grade $3 / 4$ toxicities ( 1 treated with nivolumab $1 \mathrm{mg} / \mathrm{kg}$, and 7 with nivolumab $5 \mathrm{mg}$ / $\mathrm{kg}$ ). Of the patients treated with the pazopanib combination, $20 \%$ had to discontinue because of toxicities. The overall response rate was similar, $52 \%$ for sunitinib and $45 \%$ for pazopanib patients with the duration of response ranging from 2.8 to 12.4 months (sunitinib) and 2.8 to 15.9 months (pazopanib). Overall, the PFS at 24 weeks was $78 \%$ for patients treated in the sunitinib arm and $55 \%$ for those in the pazopanib arm [31].

In summary, the combination of nivolumab $(3 \mathrm{mg} / \mathrm{kg})$ and ipilimumab $(1 \mathrm{mg} / \mathrm{kg})$ seems to be promising and is currently being investigated in a phase III trial that compares this combination to standard first-line sunitinib treatment. Based on one phase I study, sunitinib seems be the preferred partner to be combined with nivolumab. However, even with this drug about a quarter of patients had to stop therapy because of toxicities, which may question the feasibility of the combination of tyrosine kinase inhibitors and anti-PD-1 antibodies. 
Oudard et al. [32] reported a phase II study of TG4010 (a vaccine based on a modified vaccinia virus expressing MUC1 and IL2) in combination with cytokines as first-line therapy in 37 patients with metastatic RCC. No objective clinical responses were observed. Five of the 27 evaluable patients (18\%) had stable disease for $>6$ months with TG4010 alone, and 6 of 20 patients (30\%) had stable disease for $>6$ months with TG4010 plus cytokines [32]. Another phase III trial tested whether the modified vaccinia Ankara encoding the tumour antigen 5T4 (MVA-5T4) could improve OS if added to standard first-line therapy. This double-blind trial recruited 733 patients but no survival impact was observed. A subgroup analysis suggested that patients with a higher 5T4-specific antibody response benefited from the experimental treatment, but further development of MVA-5T4 was not pursued [33]. One ongoing phase III trial is investigating the addition of autologous dendritic cells to sunitinib; the first results may be available in spring 2016 (NCT01582672).

Two trials are currently investigating the effect of tumour-associated peptides in advanced RCC. The compound IMA901 is a synthetic 'off-the-shelf' vaccine consisting of 10 different tumour-associated peptides. In a recent phase II trial, patients received IMA901 and granulocyte-macrophage colony-stimulating factor with or without cyclophosphamide (NCT00523159); the results of this trial are awaited. A phase III trial has investigated the addition of IMA901 to sunitinib for first-line treatment in advanced/metastatic RCC. The first results are awaited in the second half of 2015 (NCT01265901).

In summary, immunotherapies based on vaccines have not shown a significant clinical benefit in the advanced setting so far. Results from ongoing trials are awaited, especially those in combination with standard sunitinib treatment.

\section{Adjuvant Studies}

\section{Vaccines}

Several randomised trials have been conducted to test whether adjuvant immunotherapy-based treatment can prolong survival after resection of the primary RCC. Two small trials investigated autologous irradiated tumour cells in combination with Bacillus Calmette-Guérin, but none showed a clinical benefit [34, 35]. In a large randomised phase III trial, 558 patients scheduled for radical nephrectomy were enrolled at 55 centres in Germany and randomised to receive an autologous tumour cell vaccine or observation [36]. Randomization was performed before surgery and finally 379 patients (177 in the vaccination group, 202 in the control group) with a tumour $\geq 2.5 \mathrm{~cm}$ were included in the intention-to-treat analysis. PFS was significantly prolonged in the vaccination group (hazard ratio: 1.58 in favour of the vaccination group, 
95\% CI 1.05-2.37), but OS has not been reported as being prolonged [36]. Another randomised phase III trial investigated vitespen, also an autologous vaccine; the vaccine was compared to observation alone. Eight hundred and eighteen patients were enrolled and randomised from 118 centres in North America and Europe. There was no difference regarding the primary endpoint recurrence-free survival or OS [37].

\section{IFN- $\alpha$-Based Therapies}

Encouraged by the activity of IFN- $\alpha$ in advanced or metastatic RCC, 2 large randomised trials investigated adjuvant treatment with IFN- $\alpha$ compared to observation alone. However, neither of them showed any clinical benefit $[38,39]$. High-dose IL-2 similarly has not been shown to have any meaningful benefit in the adjuvant setting [40]. Combining low doses of IL-2 and IFN- $\alpha$ was also of no benefit, although a post hoc subgroup analysis suggested some benefit for younger patients with small tumours [41]. The combination of IFN- $\alpha$, IL-2 and fluorouracil did not show any benefit in a recently published EORTC trial [42]; it has even been suggested that this combination might have a detrimental effect on OS as compared to observation only [2].

In summary, there is no convincing evidence for any adjuvant immunotherapy having a beneficial effect following radical nephrectomy for RCC.

\section{Conclusion}

The development of new immunomodulatory antibodies targeting the CTLA-4 or PD-1 axis has led to a revival of research on immunotherapies in solid tumours, including RCC. Research on anti-tumour vaccines has continued in parallel. The preliminary data on these new antibodies are promising with good safety profiles and durable disease control, even though the overall response rates are low. Currently, there is no evidence that targeting the CTLA-4 or PD-1 axis provides a substantial clinical benefit compared to established treatment with tyrosine kinase or mTOR inhibitors. However, this may change with key trials ongoing, which are investigating the role of these new immunotherapy agents. These trials include: CheckMate 214 (nivolumab + ipilimumab versus sunitinib in the first-line setting; NCT02231749) and CheckMate 025 (nivolumab versus everolimus after the failure of anti-VEGF treatment; NCT01668784). Interestingly, the primary endpoint (PFS) in the CheckMate 214 trial is primarily powered on patients with intermediate/poor risk and patients are only required to have at least a clear-cell component in their tumour. Therefore, this study will enrol patients that are usually underrepresented in RCC trials. Two large randomised phase III trials investigating the benefit of the anti-tumour vaccine (IMA901; NCT01265901) or autologous dendritic cells (AGS-003; NCT01582672) in addition to sunitinib are expected to be reported in 2015 and 2016, respectively. 


\section{References}

1 Escudier B, Kataja V: Renal cell carcinoma : ESMO clinical practice guidelines for diagnosis, treatment and follow-up clinical practice guidelines. Ann Oncol 2014;25(suppl 3):49-56.

$>2$ Atzpodien J, Schmitt E, Gertenbach U, Fornara P, Heynemann $\mathrm{H}$, Maskow A, et al: Adjuvant treatment with interleukin-2- and interferon-alpha2a-based chemoimmunotherapy in renal cell carcinoma post tumour nephrectomy: results of a prospectively randomised trial of the German Cooperative Renal Carcinoma Chemoimmunotherapy Group (DGCIN). Br J Cancer 2005;92:843-846.

-3 Steineck G, Strander H, Carbin BE, Borgström E, Wallin L, Achtnich U, et al: Recombinant leukocyte interferon alpha-2a and medroxyprogesterone in advanced renal cell carcinoma: a randomized trial. Acta Oncol 1990;29:155-162.

4 Pyrhönen S, Salminen E, Ruutu M, Lehtonen T, Nurmi M, Tammela T, et al: Prospective randomized trial of interferon alfa-2a plus vinblastine versus vinblastine alone in patients with advanced renal cell cancer. J Clin Oncol 1999;17: 2859-2867.

5 Coppin C, Porzsolt F, Awa A, Kumpf J, Coldman A, Wilt T: Immunotherapy for advanced renal cell cancer. Cochrane Database Syst Rev 2005:CD001425.

-6 Yang JC, Sherry RM, Steinberg SM, Topalian SL, Schwartzentruber DJ, Hwu P, et al: Randomized study of high-dose and low-dose interleukin-2 in patients with metastatic renal cancer. J Clin Oncol 2003;21:3127-3132.

7 McDermott DF, Regan MM, Clark JI, Flaherty LE, Weiss GR, Logan TF, et al: Randomized phase III trial of high-dose interleukin-2 versus subcutaneous interleukin-2 and interferon in patients with metastatic renal cell carcinoma. J Clin Oncol 2005;23: 133-141.

8 Fyfe G, Fisher RI, Rosenberg SA, Sznol M, Parkinson DR, Louie AC: Results of treatment of 255 patients with metastatic renal cell carcinoma who received high-dose recombinant interleukin-2 therapy. J Clin Oncol 1995;13:688-696.

-9 Fisher RI, Rosenberg SA, Fyfe G: Long-term survival update for high-dose recombinant interleukin-2 in patients with renal cell carcinoma. Cancer J Sci Am 2000;6(suppl 1):55-57.

10 Gore ME, Griffin CL, Hancock B, Patel PM, Pyle L, Aitchison $\mathrm{M}$, et al: Interferon alfa-2a versus combination therapy with interferon alfa-2a, interleukin-2, and fluorouracil in patients with untreated metastatic renal cell carcinoma (MRC RE04/EORTC GU 30012): an open-label randomised trial. Lancet 2010 375:641-648
11 Escudier B, Pluzanska A, Koralewski P, Ravaud A, Bracarda S, Szczylik C, et al: Bevacizumab plus interferon alfa-2a for treatment of metastatic renal cell carcinoma: a randomised, double-blind phase III trial. Lancet 2007;370:2103-2111.

12 Rini BI, Halabi S, Rosenberg JE, Stadler WM, Vaena DA, Ou SS, et al: Bevacizumab plus interferon alfa compared with interferon alfa monotherapy in patients with metastatic renal cell carcinoma: CALGB 90206. J Clin Oncol 2008;26:5422-5428.

13 Hodi FS, O’Day SJ, McDermott DF, Weber RW, Sosman JA, Haanen JB, et al: Improved survival with ipilimumab in patients with metastatic melanoma. $\mathrm{N}$ Engl J Med 2010;363:711-723.

14 Robert C, Ribas A, Wolchok JD, Hodi FS, Hamid O, Kefford R, et al: Anti-programmed-death-receptor-1 treatment with pembrolizumab in ipilimumab-refractory advanced melanoma: a randomised dosecomparison cohort of a phase 1 trial. Lancet 2014; 384:1109-1117.

15 Robert C, Thomas L, Bondarenko I, O’Day S, Weber J, Garbe C, et al: Ipilimumab plus dacarbazine for previously untreated metastatic melanoma. N Engl J Med 2011;364:2517-2526.

16 Robert C, Long GV, Brady B, Dutriaux C, Maio M, Mortier L, et al: Nivolumab in previously untreated melanoma without BRAF mutation. N Engl J Med 2015;372:320-330.

17 Ansell SM, Lesokhin AM, Borrello I, Halwani A, Scott EC, Gutierrez M, et al: PD-1 blockade with nivolumab in relapsed or refractory Hodgkin's lymphoma. N Engl J Med 2015;372:311-319.

18 FDA: FDA expands approved use of Opdivo to treat lung cancer. 2015. http://www.fda.gov/newsevents/ newsroom/pressannouncements/ucm436534.htm.

19 Yang JC, Hughes M, Kammula U, Royal R, Sherry RM, Topalian SL, et al: Ipilimumab (anti-CTLA4 antibody) causes regression of metastatic renal cell cancer associated with enteritis and hypophysitis. J Immunother 2007;30:825-830.

20 Rini BI, Stein M, Shannon P, Eddy S, Tyler A, Stephenson JJ, et al: Phase 1 dose-escalation trial of tremelimumab plus sunitinib in patients with metastatic renal cell carcinoma. Cancer 2011;117:758767.

21 Topalian SL, Hodi FS, Brahmer JR, Gettinger SN, Smith DC, McDermott DF, et al: Safety, activity, and immune correlates of anti-PD-1 antibody in cancer. N Engl J Med 2012;366:2443-2454. 
22 Drake CG, McDermott DF, Sznol M, Choueiri TK, Kluger HM, Powderly JD, et al: Survival, safety, and response duration results of nivolumab (antiPD-1; BMS-936558; ONO-4538) in a phase I trial in patients with previously treated metastatic renal cell carcinoma (mRCC): long-term patient follow-up (abstract). J Clin Oncol 2013;31(suppl): 4514.

23 Motzer RJ, Rini BI, McDermott DF, Redman BG, Kuzel T, Harrison MR, et al: Nivolumab for metastatic renal cell carcinoma (mRCC): results of a randomized, dose-ranging phase II trial (abstract). J Clin Oncol 2014;32(suppl 15):5009.

24 Cho DC, Sosman JA, Sznol M, Gordon MS, Hollbecque A, Hamid $\mathrm{O}$, et al: Clinical activity, safety, and biomarkers of MPDL3280A, an engineered PDL1 antibody in patients with metastatic renal cell carcinoma (mRCC) [abstract]. J Clin Oncol 2013; 31(suppl):4505.

25 Lieu C, Bendell J, Powderly JD, Pishvaian MJ, Hochster H, Eckhardt SG, et al: Safety and efficacy, of MPDL3280A (anti-PDL1) in combination with bevacizumab (BEV) and/or chemotherapy (CHEMO) in patients (PTS) with locally advanced or metastastic solid tumours. Ann Onc 2014;25: iv361-iv372.

-26 Brahmer JR, Tykodi SS, Chow LQM, Hwu W-J, Topalian SL, Hwu P, et al: Safety and activity of antiPD-L1 antibody in patients with advanced cancer. N Engl J Med 2012;366:2455-2465.

-27 Thompson RH, Kuntz SM, Leibovich BC, Dong H, Lohse CM, Webster WS, et al: Tumor B7-H1 is associated with poor prognosis in renal cell carcinoma patients with long-term follow-up. Cancer Res 2006; 66:3381-3385.

28 Choueiri TK, Figueroa DJ, Fay AP, Signoretti S, Liu Y, Gagnon R, et al: Correlation of PD-L1 tumor expression and treatment outcomes in patients with renal cell carcinoma receiving sunitinib or pazopanib: results from COMPARZ, a randomized controlled trial. Clin Cancer Res 2015;21:1071-1077.

29 Choueiri TK, Fay AP, Gray KP, Callea M, Ho TH, Albiges L, et al: PD-L1 expression in nonclear-cell renal cell carcinoma. Ann Oncol 2014;25:21782184.

30 Hammers H, Plimack ER, Infante JR, Ernstoff B, Rini BI, McDermott DF, et al: Phase 1 study of nivolumab in combination with ipilimumab in metastatic renal cell carcinoma (MRCC). ASCO Meeting Abstracts. Ann Oncol 2014;25(suppl 4):4504.
31 Amin A, Plimack ER, Infante JR, Ernstoff MS, Rini BI, McDermott DF, et al: Nivolumab (anti-PD-1; BMS-936558, ONO-4538) in combination with sunitinib or pazopanib in patients (pts) with metastatic renal cell carcinoma (mRCC) [abstract]. J Clin Oncol 2014;32(suppl):1-15.

32 Oudard S, Rixe O, Beuselinck B, Linassier C, Banu E, Machiels J-P, et al: A phase II study of the cancer vaccine TG4010 alone and in combination with cytokines in patients with metastatic renal clear-cell carcinoma: clinical and immunological findings. Cancer Immunol Immunother 2011;60:261-271.

33 Amato RJ, Hawkins RE, Kaufman HL, Thompson JA, Tomczak P, Szczylik C, et al: Vaccination of metastatic renal cancer patients with MVA-5T4: a randomized, double-blind, placebo-controlled phase III study. Clin Cancer Res 2010;16:5539-5547.

34 Adler A, Gillon G, Lurie H, Shaham J, Loven D, Shachter Y, et al: Active specific immunotherapy of renal cell carcinoma patients: a prospective randomized study of hormono-immuno-versus hormonotherapy: preliminary report of immunological and clinical aspects. J Biol Response Mod 1987;6:610624.

35 Galligioni E, Quaia M, Merlo A, Carbone A, Spada A, Favaro D, et al: Adjuvant immunotherapy treatment of renal carcinoma patients with autologous tumor cells and Bacillus Calmette-Guerin: five-year results of a prospective randomized study. Cancer 1996;77:2560-2566.

36 Jocham D, Richter A, Hoffmann L, Iwig K, Fahlenkamp D, Zakrzewski G, et al: Adjuvant autologous renal tumour cell vaccine and risk of tumour progression in patients with renal-cell carcinoma after radical nephrectomy: phase III, randomised controlled trial. Lancet 2004;363:594-599.

37 Wood C, Srivastava P, Bukowski R, Lacombe L, Gorelov AI, Gorelov S, et al: An adjuvant autologous therapeutic vaccine (HSPPC-96; vitespen) versus observation alone for patients at high risk of recurrence after nephrectomy for renal cell carcinoma: a multicentre, open-label, randomised phase III trial. Lancet 2008;372:145-154.

38 Pizzocaro G, Piva L, Colavita M, Ferri S, Artusi R, Boracchi $\mathrm{P}$, et al: Interferon adjuvant to radical nephrectomy in Robson stages II and III renal cell carcinoma: a multicentric randomized study. J Clin Oncol 2001;19:425-431.

39 Messing EM, Manola J, Wilding G, Propert K, Fleischmann J, Crawford ED, et al: Phase III study of interferon alfa-NL as adjuvant treatment for resectable renal cell carcinoma: an Eastern Cooperative Oncology Group/Intergroup Trial. J Clin Oncol 2003;21: 1214-1222. 
40 Clark JI, Atkins MB, Urba WJ, Creech S, Figlin RA, Dutcher JP, et al: Adjuvant high-dose bolus interleukin-2 for patients with high-risk renal cell carcinoma: a cytokine working group randomized trial. J Clin Oncol 2003;21:3133-3140.

41 Passalacqua R, Buzio C, Buti S, Labianca R, Porta C, Boni C, et al: Adjuvant low-dose interleukin-2 (IL-2) plus interferon-alpha (IFN- $\alpha$ ) in operable renal cell cancer (RCC): a phase III, randomized, multicenter, independent trial of the Italian Oncology Group for Clinical Research (GOIRC). J Immunother 2014;37: 440-447.
42 Aitchison M, Bray CA, van Poppel H, Sylvester R, Graham J, Innes C, et al: Adjuvant 5-flurouracil, alpha-interferon and interleukin-2 versus observation in patients at high risk of recurrence after nephrectomy for renal cell carcinoma: results of a phase III randomised European Organisation for Research and Treatment of Cancer. Eur J Cancer 2014;50:7077.

Prof. Martin Gore, PhD, FRCP

Medical Oncology

Royal Marsden Hospital

Fulham Road, SW3 6JJ London (UK)

E-Mail martin.gore@rmh.nhs.uk 